\title{
A VALIDATED STABILITY INDICATING ULTRA-PERFORMANCE LIQUID CHROMATOGRAPHIC METHOD FOR SIMULTANEOUS DETERMINATION OF METFORMIN HYDROCHLORIDE AND EMPAGLIFLOZIN IN BULK DRUG AND TABLET DOSAGE FORM
}

\author{
N. MADANA GOPAL ${ }^{1 *}$, C. SRIDHAR $^{2}$ \\ ${ }^{1}$ Research Scholar, Rayalaseema University, Kurnool. Andhra Pradesh, India, ${ }^{2}$ Department of Pharmaceutical Analysis, Sri Padmavathi \\ School of Pharmacy, Tirupathi, Andhra Pradesh, India \\ Email: madanapharma@gmail.com \\ Received: 02 Feb 2017, Revised and Accepted: 17 Apr 2017
}

\section{ABSTRACT}

Objective: To develop a simple, precise, accurate, method was developed and validated for analysis of metformin hydrochloride (MET) and empagliflozin in (EMPA) in bulk and tablet dosage form.

Methods: The method used a reverse phase column, dikma C18 $(50 \times 2.1 \mathrm{~mm}, 1.8 \mu)$, a mobile phase comprising of phosphate buffer (pH-3): methanol $(30: 70 \mathrm{v} / \mathrm{v})$ flow rate of $1.0 \mathrm{ml} / \mathrm{min}$ and a detection wavelength of $240 \mathrm{~nm}$ using a photodiode array detector. The proposed method was validated for various parameters like linearity, precision, accuracy, robustness, ruggedness, detection, quantification limits, stability studies, formulation analysis as per International Conference on Harmonization (ICH) guidelines.

Results: The retention time was found to be $1.189 \mathrm{~min}$ and $1.712 \mathrm{~min}$ for MET and EMPA respectively. The proposed method was found to be having linearity in the concentration range of $500-2500 \mu \mathrm{g} / \mathrm{ml}$ for MET $\left(\mathrm{r}^{2}=0.989\right)$ and $5-25 \mu \mathrm{g} / \mathrm{ml}$ for EMPA ( $\left.\mathrm{r}^{2}=0.994\right)$, respectively. The mean $\%$ recoveries obtained were found to be $100.35-100.48 \%$ for MET and $99.80-101.30 \%$ for EMPA respectively. Stress testing which covered acid, base, peroxide, photolytic and thermal degradation was performed on under test to prove the specificity of the method and the degradation was achieved. The developed method has been statistically validated according to International Conference on Harmonization (ICH) guidelines.

Conclusion: Thus, the proposed method can be successfully applied for the stability indicating the simultaneous determination of MET and EMPA in bulk and combined tablet dosage form and in the routine quality control analysis.

Keywords: Empagliflozin, Metformin hydrochloride, Reversed-phase ultra-performance liquid chromatography, Validation

(C) 2017 The Authors. Published by Innovare Academic Sciences Pvt Ltd. This is an open access article under the CC BY license (http://creativecommons.org/licenses/by/4.0/) DOI: http://dx.doi.org/10.22159/ijap.2017v9i3.17441

\section{INTRODUCTION}

Metformin (MET) hydrochloride is chemically named as (3-(diamino methylidene)-1, 1-dimethylguanidine hydrochloride. It has a molecular formula of $\mathrm{C}_{4} \mathrm{H}_{12} \mathrm{ClN}_{5}$ and the molecular weight is 165.62 $\mathrm{g} / \mathrm{mol}$. MET is an oral anti-hyperglycemic agent (Type 2 diabetes) belongs to a class of biguanides and useful for treating non-insulin dependent diabetes mellitus. MET decreases blood glucose levels by decreasing hepatic glucose production, decreasing intestinal absorption of glucose, and improving insulin sensitivity by increasing peripheral glucose uptake and utilization. These effects are mediated by the initial activation by MET of AMP-activated protein kinase, a liver enzyme that plays an important role in insulin signaling, whole body energy balance, and the metabolism of glucose and fats [1-5].

Empagliflozin (EMPA) is chemically named as 1-chloro-4-[b-Dglucopyranos-1-yl]-2-[4-([S]-tetrahydrofuran-3-yl-oxy) benzyl]benzene (fig. 2). It has a molecular formula of $\mathrm{C}_{23} \mathrm{H}_{27} \mathrm{ClO}_{7}$ and molecular weight is $450.912 \mathrm{~g} / \mathrm{mol}$. Empagliflozin is an orally administered selective sodium glucose cotransporter-2 (SGLT-2) inhibitor, which lowers blood glucose in people with type 2 diabetes by blocking the reabsorption of glucose in the kidneys and promoting the excretion of excess glucose in the urine $[6,8]$. The sodium glucose cotransporter 2 (SGLT2), located in the proximal tubule of the nephron, is estimated to facilitate- $90 \%$ of this reabsorption $[9,10]$. It is a potent and selective competitive inhibitor of the SGLT2 protein. Sodium-glucose co-transporter 2 (SGLT2) inhibitors offer an insulin-independent mechanism for improving blood glucose levels since they promote urinary glucose excretion (UGE) by inhibiting glucose reabsorption in the kidney. In addition to glucose control, SGLT2 inhibitors are associated with weight loss and blood pressure reductions and do not increase the risk of hypoglycemia [9].

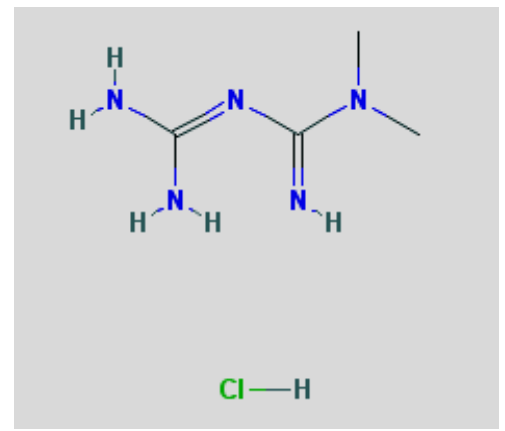

Fig. 1: Metformin (MET) hydrochloride structure from pub chem

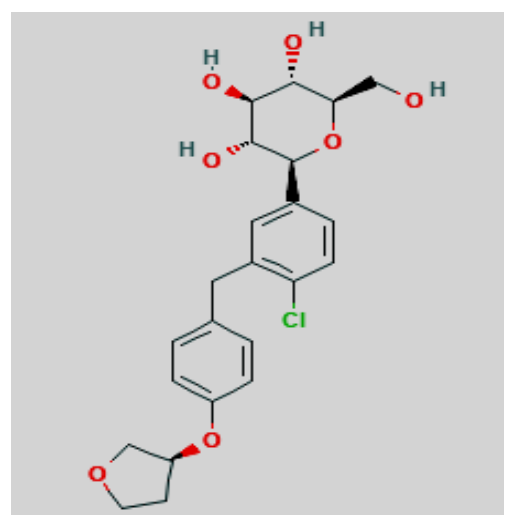

Fig. 2: Empagliflozin (EMPA) structure from pubchem 
Literature survey revealed that few analytical methods are reported for analysis of both the drugs alone as well as in combination using ultraviolet spectrophotometry $[15,22]$, high-pressure liquid chromatography (HPLC) $[10,12,17-19,23,25,26]$ and ultrapressure liquid chromatography [11]. To date, there have been no published reports about the simultaneous estimation of metformin $\mathrm{HCl}$ and empagliflozin by reverse phase ultra performance liquid chromatography (RP-UPLC) in bulk drug and in pharmaceutical dosage forms. Hence, an attempt has been made to develop a new method for simultaneous estimation and validation of MET and EMPA in tablet formulation in accordance with the International Conference on Harmonization (ICH) guidelines [26].

\section{MATERIALS AND METHODS}

\section{Chemicals and reagents}

Metformin $\mathrm{HCl}$ and empagliflozin were procured gift sample from pharma train research solutions, Hyderabad. Tablets were procured from a local pharmacy containing $1000 \mathrm{mg}$ (Metformin $\mathrm{HCl}$ ) and 10 mg (Empagliflozin). All solvents were of HPLC grade and all reagents were of analytical grade. Orthophosphoric acid was obtained from Merck (India), water and methanol for HPLC were obtained from lichrosolv (Merck), potassium dihydrogen orthophosphate was obtained from finer chemical Ltd and acetonitrile was obtained from molychem. All solvents and solutions were filtered through a membrane filter (Millipore Millex-HV filter units, $0.45 \mu \mathrm{m}$ pore size; nylon) and degassed before use.

\section{Instrumentation}

The UPLC was carried out on the waters with empower 2695 separation module, auto Sampler and photodiode array (PDA) detector were used in the analysis. Ultraviolet-visible spectrophotometer (Labindia), Balance (Afcoset ER-200A) and pH meter (Adwa-AD 1020).
Preparation of the metformin $\mathrm{HCl}$ and empagliflozin standard and sample solution

Accurately weighed 10 tablets crushed in mortor and transferred equivalent to $1000 \mathrm{mg}$ of metformin $\mathrm{HCl}$ and $10 \mathrm{mg}$ empagliflozin sample into a $100 \mathrm{ml}$ clean dry volumetric flask added about $70 \mathrm{ml}$ of diluent and sonicated to dissolve it completely and made the volume up to the mark with the same solvent(Stock solution). Pipetted out $1.5 \mathrm{ml}$ of metformin $\mathrm{HCl}$ and empagliflozin of the above stock solution into a $10 \mathrm{ml}$ volumetric flask and diluted up to the mark with diluent. In a similar manner working standard solutions of metformin $\mathrm{HCl}$ and empagliflozin were prepared $(150 \mu \mathrm{g} / \mathrm{ml}$ MET and $15 \mu \mathrm{g} / \mathrm{ml}$ of EMPA) $[11,13,15,16]$.

\section{Chromatographic conditions}

Chromatographic conditions the UPLC system consisted of 2695 separation module, autosampler and PDA detector. The wavelength of detection as set at $240 \mathrm{~nm}$. Separation was carried out in dikma C18 $(50 \times 2.1 \mathrm{~mm}, 1.8 \mu)$ and the retention time (RT) of metformin $\mathrm{HCl}$ and empagliflozinin was found to be $1.189 \mathrm{~min}$ and $1.712 \mathrm{~min}$ respectively shown in fig. 3, using mobile phase consisting phosphate buffer and methanol, $\mathrm{pH} 3.0$ in the ratio of $30: 70 \mathrm{v} / \mathrm{v}$ at a flow rate of $1 \mathrm{ml} / \mathrm{min}$ with UV detection at $240 \mathrm{~nm}$. The mobile phase was filtered through $0.45 \mu$ filter under vacuum filtration [18, 19, 21].

\section{RESULTS AND DISCUSSION}

\section{Method validation}

The developed method was validated as per ICH guidelines for its system suitability, linearity, accuracy, precision, and robustness, limit of detection and limit of quantification by using the following procedures [26].

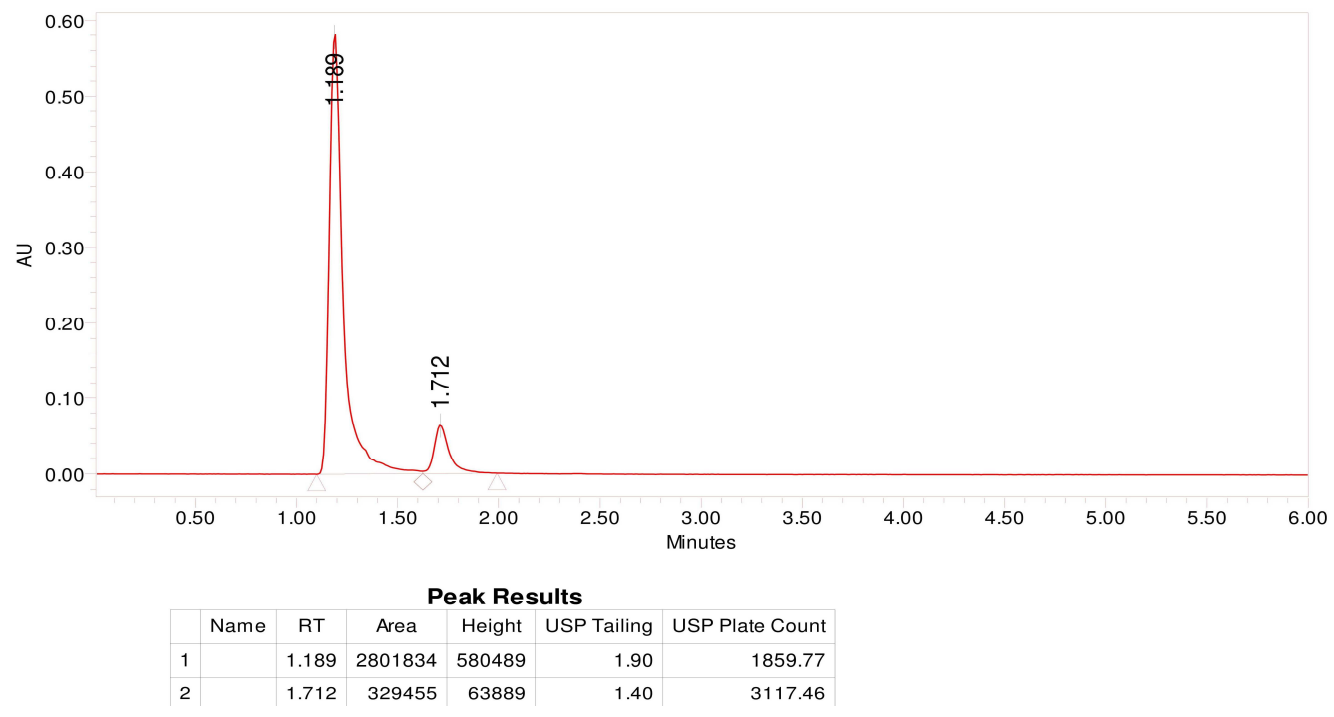

Fig. 3: Chromatogram of metformin $\mathrm{HCl}$ and empagliflozinin

\begin{abstract}
Accuracy
Accuracy of the method was established by performing recovery studies of ICH guidelines. Spiked samples were prepared by preanalyzed sample solutions with the pure drug at three different concentration levels each in triplicate. The \% mean recovery of metformin $\mathrm{HCl}$ (100.35-100.48\%) and empagliflozin (99.80$101.30 \%$ ) at each level were within the limits of $98 \%$ and $102 \%$ indicating that the method is more accurate shown in table 1 , when compared with metformin $\mathrm{HCl}$ (100.64-100.89\%) and empagliflozin (99.95-101.34) by hplc [27] method. The current research work indicates that retention time value is less than 2
\end{abstract}

min which is a good recovery value of the existing method in comparison with HPLC method.

\section{Precision}

The Intraday precision was demonstrated by injecting standard solutions of metformin $\mathrm{HCl}$ and empagliflozin with $1500 \mu \mathrm{g} / \mathrm{ml}$ and $15 \mu \mathrm{g} / \mathrm{ml}$, respectively as per the test procedure and recording the chromatograms of six standard solutions. The \% relative standard deviation (RSD) of metformin $\mathrm{HCl}$ and empagliflozin was found to be 1 and 1.1 respectively shown in table 2 . \% RSD values were within the limits and the method was found to be precise. 
Table 1: Accuracy data of metformin $\mathrm{HCl}$ and empagliflozin

\begin{tabular}{|c|c|c|c|c|c|}
\hline \multicolumn{6}{|l|}{ Metformin HCl } \\
\hline $\begin{array}{l}\text { \% concentration (at specification Level), } \\
(n=3)\end{array}$ & Area & Amount added (mg) & Amount found (mg) & $\%$ recovery & \% RSD \\
\hline $50 \%$ & 2403115 & 500 & 501.76 & 100.35 & 1.21 \\
\hline $100 \%$ & 4830189 & 1000 & 1008.52 & 100.85 & 1.29 \\
\hline $150 \%$ & 7218887 & 1500 & 1507.27 & 100.48 & 0.63 \\
\hline \multicolumn{6}{|l|}{ Empagliflozin } \\
\hline $50 \%$ & 102326 & 5.0 & 5.06 & 101.30 & 1.16 \\
\hline $100 \%$ & 201600 & 10.0 & 9.98 & 99.80 & 1.29 \\
\hline $150 \%$ & 304187 & 15.0 & 15.07 & 100.47 & 0.64 \\
\hline
\end{tabular}

Table 2: Precision data of metformin $\mathrm{HCl}$ and empagliflozin

\begin{tabular}{lll}
\hline S. No. & Metformin HCl & Empagliflozin \\
\cline { 2 - 3 } & Area & Area \\
\hline 1 & 4669547 & 205555 \\
2 & 4633682 & 213714 \\
3 & 4711857 & 202403 \\
4 & 4586290 & 191233 \\
5 & 4690109 & 197507 \\
6 & 4674377 & 205189 \\
mean $\pm S D,(n=6)$ & $4660977.0 \pm 44751.8$ & $192600.0 \pm 13583.0$ \\
\hline RSD & 1 & 1.1 \\
\hline
\end{tabular}

\section{Intermediate precision}

The intermediate precision of the analytical method was determined by performing method precision on in three successive days by different analysts under same experimental condition by injecting six replicate standard preparations was determined and the mean \% RSD of metformin $\mathrm{HCl}(1500 \mu \mathrm{g} / \mathrm{ml})$ and empagliflozin $(15 \mu \mathrm{g} / \mathrm{ml})$ was found to be 0.9 and 0.8 respectively shown in table 3.\% RSD values were within the limits and the method was found to be precise.

Table 3: Intermediate precision data of metformin $\mathrm{HCl}$ and empagliflozin

\begin{tabular}{lll}
\hline S. No. & Metformin HCl & Empagliflozin \\
\cline { 2 - 3 } & Area & Area \\
\hline 1 & 4744291 & 205724 \\
2 & 4657794 & 204813 \\
3 & 4797415 & 204018 \\
4 & 4706370 & 191618 \\
5 & 4721262 & 201052 \\
mean \pm SD, $(\mathrm{n}=6)$ & 4781858 & $205252.9 \pm 16346.1$ \\
\%RSD & $4768164.9 \pm 86790.3$ & 0.8 \\
\hline
\end{tabular}

\section{Linearity}

The measurement of linearity was evaluated by analyzing different concentrations of the standard solution of metformin $\mathrm{HCl}$ and empagliflozin. For both the drugs, the Beer-lamberts law was obeyed in the concentration range $500-2500 \mu \mathrm{g} / \mathrm{ml}$ and $5-25 \mu \mathrm{g} / \mathrm{ml}$ for metformin $\mathrm{HCl}$ and empagliflozin respectively. The linearity of the proposed UPLC method was constructed by considering concentration $(\mu \mathrm{g} / \mathrm{ml})$ on X-axis and peak area on Y-axis. The regression coefficient was considered to be 0.98 over a concentration range of $500-2500 \mu \mathrm{g} / \mathrm{ml}$ (MET) and 0.99 over a concentration range of $5-25 \mu \mathrm{g} / \mathrm{ml}$ (EMPA). The representative linearity equation was found to be $y=2656 x+53186$ (MET) and $y=$ $12865 x+27421$ (EMPA) as showed in fig. 4 and 5 and the corresponding data were shown in table 4 . For both the methods the $\%$ RSD was found to be within the acceptable theoretical limits of $\leq$ $2 \%$, which meet the method validation acceptance criteria and hence the method was said to be linear for both the drugs.

\section{Limit of detection (LOD) and limit of quantification (LOQ)}

The LOD is calculated using the formula 3.3 times $\sigma / \mathrm{s}$ where " $\sigma$ " is the standard deviation of the intercept obtained for calibration curve and "s" is the slope of the calibration curve. Similarly, LOQ is calculated using the formula 10 times $\sigma / \mathrm{s}$. The calculated LOD and LOQ for MET and EMPA using the proposed method were found to be $0.2626 \mu \mathrm{g} / \mathrm{ml}, 0.795 \mu \mathrm{g} / \mathrm{ml}$ and $0.02615 \mu \mathrm{g} / \mathrm{ml}, 0.0792 \mu \mathrm{g} / \mathrm{ml}$ respectively. The results obtained were presented in table 5 .

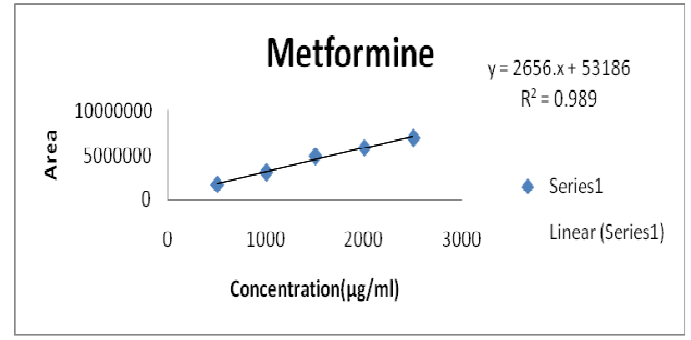

Fig. 4: Linearity graph for metformin $\mathrm{HCl}$

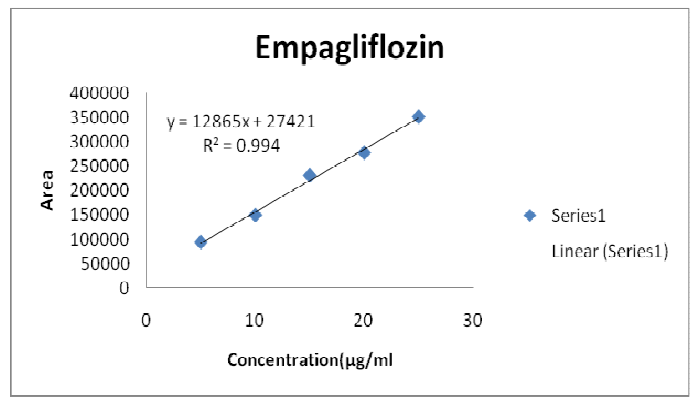

Fig. 5: Linearity graph for Empagliflozin 
Table 4: Linearity data of metformin $\mathrm{HCl}$ and empagliflozin

\begin{tabular}{|c|c|c|c|c|}
\hline \multirow[t]{2}{*}{ S. No. } & \multicolumn{2}{|l|}{ Metformin $\mathrm{HCl}$} & \multicolumn{2}{|l|}{ Empagliflozin } \\
\hline & Concentration $(\mu \mathrm{g} / \mathrm{ml})$ & Area & Concentration $(\mu \mathrm{g} / \mathrm{ml})$ & Area \\
\hline 1 & 500 & 1737625 & 5 & 93475 \\
\hline 2 & 1000 & 3100790 & 10 & 149362 \\
\hline 3 & 1500 & 4887985 & 15 & 230699 \\
\hline 4 & 2000 & 5851773 & 20 & 277360 \\
\hline 5 & 2500 & 7002614 & 25 & 351109 \\
\hline Correlation coefficient & & 0.989 & & 0.994 \\
\hline
\end{tabular}

Table 5: LOD and LOQ data of metformin $\mathrm{HCl}$ and empagliflozin

\begin{tabular}{lllll}
\hline Drug name & Standard deviation( $\boldsymbol{\sigma})$ & Slope(s) & Intercept & LOD $(\boldsymbol{\mu g} / \mathbf{m l})$ \\
\hline Metformin. HCl & 2111167 & 2656 & 53186 & 0.2623 \\
Empagliflozin & 101970.2 & 12865 & 27421 & 0.02615 \\
\hline
\end{tabular}

\section{Robustness}

Robustness were measured by making small, but deliberate changes in flow rate were varied at $0.9 \mathrm{ml} / \mathrm{min}$ to $1.1 \mathrm{ml} / \mathrm{min}$ and $10 \%$ organic content in mobile phase affected the method significantly. This deliberate change in the above parameters has no significant effect on the peak tailing, peak area and theoretical plates and finally the method was found to be robust and the results were shown in table 6.

Table 6: Robustness data of metformin $\mathrm{HCl}$ and empagliflozin

\begin{tabular}{llll}
\hline Parameter & Metformin HCl & Empagliflozin \\
\cline { 2 - 4 } & USP Plate count & USP tailing & USP Plate count \\
\hline Less flow rate $(0.8 \mathrm{ml} / \mathrm{min})$ & 2001.88 & 1.13 & 4005.09 \\
More flow rate $(1.2 \mathrm{ml} / \mathrm{min})$ & 2796.68 & 1.09 & 3430.48 \\
Mobile phase(10\% less) & 2041.88 & 1.13 & 4025.09 \\
Mobile phase(10\% more) & 2796.68 & 1.09 & 1.21 \\
\hline
\end{tabular}

\section{Degradation studies}

ICH degradation was attempted to various stress conditions such as acid hydrolysis $(0.1 \mathrm{~N} \mathrm{HCl})$, base hydrolysis $(0.1 \mathrm{~N} \mathrm{NaOH})$, oxidative hydrolysis $(3 \% \mathrm{H} 2 \mathrm{O} 2)$, thermal degradation (heated at $110^{\circ} \mathrm{C}$ for 24 h) and photolytic degradation (overall illumination of $\geq 210 \mathrm{~W} \mathrm{~h} / \mathrm{m} 2$ at $25{ }^{\circ} \mathrm{C}$ for $7 \mathrm{~d}$ with UV radiation at $320-400 \mathrm{~nm}$ ), to evaluate the ability of the proposed method to separate MET and EMPA from its degradation products [25]. It was observed that the drug degrades as shown by the decreased areas in the peaks when compared with peak areas of the same concentration of the non-degraded drug, with additional degradation peaks. Percent degradation was calculated by comparing the areas of the degraded peaks at each degradation condition with the corresponding areas of the peaks of both the drugs under non-degradation condition. Comparatively, more degradation was found with base, peroxide, photo, thermal for EMPA and with thermal for MET. There was no interference in any of the degradation products of the stress conditions tested in the current study. Thus, the developed method of analytical determination of MET and EMPA was established to be specific and stability-indicating. The results are shown in table 7 and fig. $6,7,8,9,10[20,22]$.

Table 7: Degradation data of metformin $\mathrm{HCl}$ and empagliflozin

\begin{tabular}{|c|c|c|c|c|}
\hline \multirow[t]{2}{*}{ Stress condition } & \multicolumn{2}{|c|}{ Metformin HCl } & \multicolumn{2}{|c|}{ Empagliflozin } \\
\hline & \% assay & \% degraded & \% assay & \% degraded \\
\hline Standard & 100 & - & 100 & - \\
\hline Acid & 97.6 & 2.40 & 94.03 & 5.97 \\
\hline Base & 94.56 & 5.44 & 91.3 & 8.70 \\
\hline Peroxide & 95.04 & 4.96 & 92.14 & 7.86 \\
\hline Thermal & 92.52 & 7.48 & 89.51 & 10.49 \\
\hline Photo & 95.15 & 4.85 & 91.04 & 8.96 \\
\hline
\end{tabular}

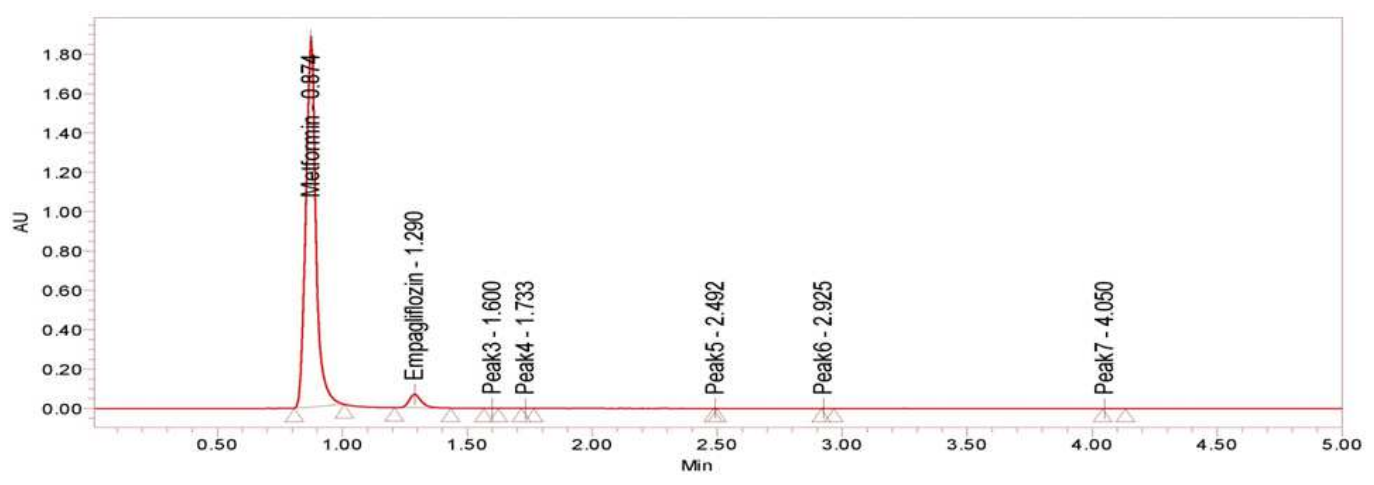

Fig. 6: Chromatogram of acid degradation 


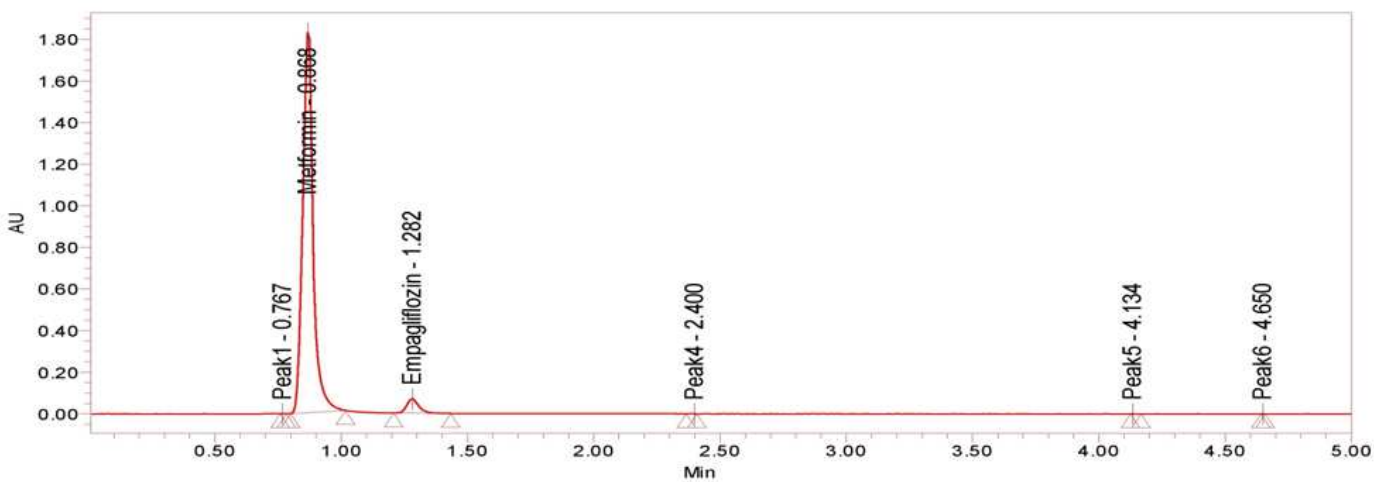

Fig. 7: Chromatogram of base degradation

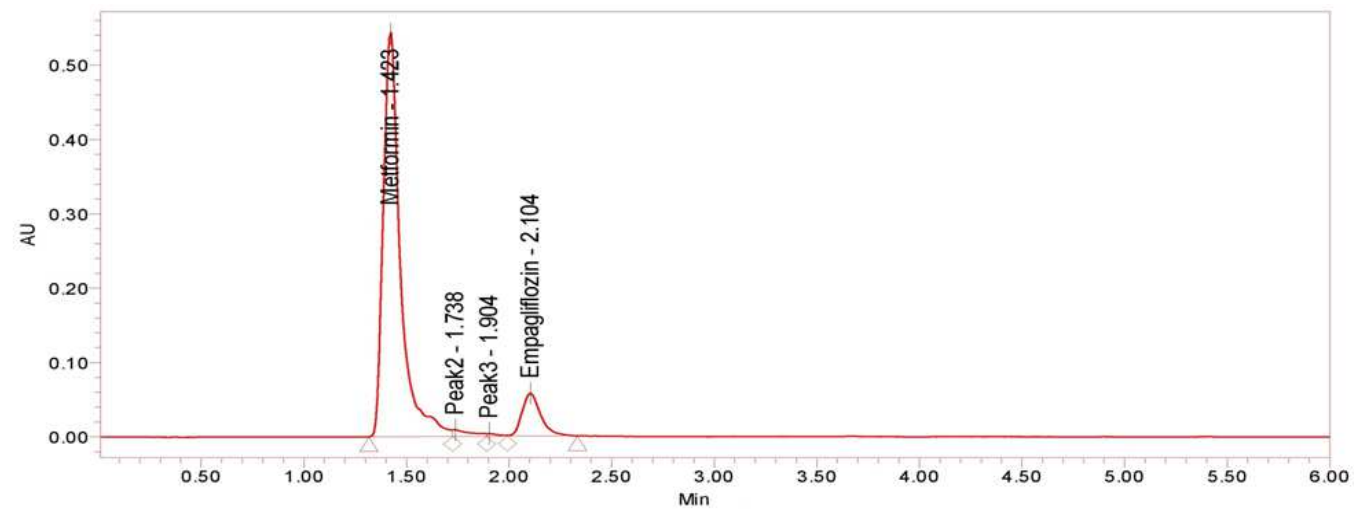

Fig. 8: Chromatogram of peroxide degradation

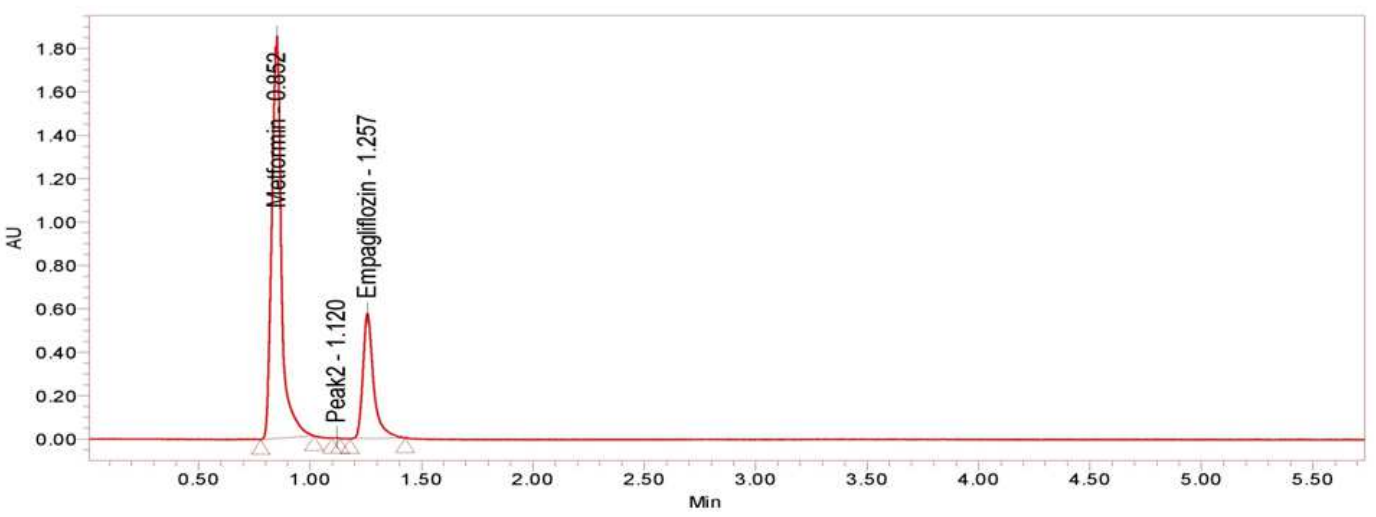

Fig. 9: Chromatogram of photo degradation

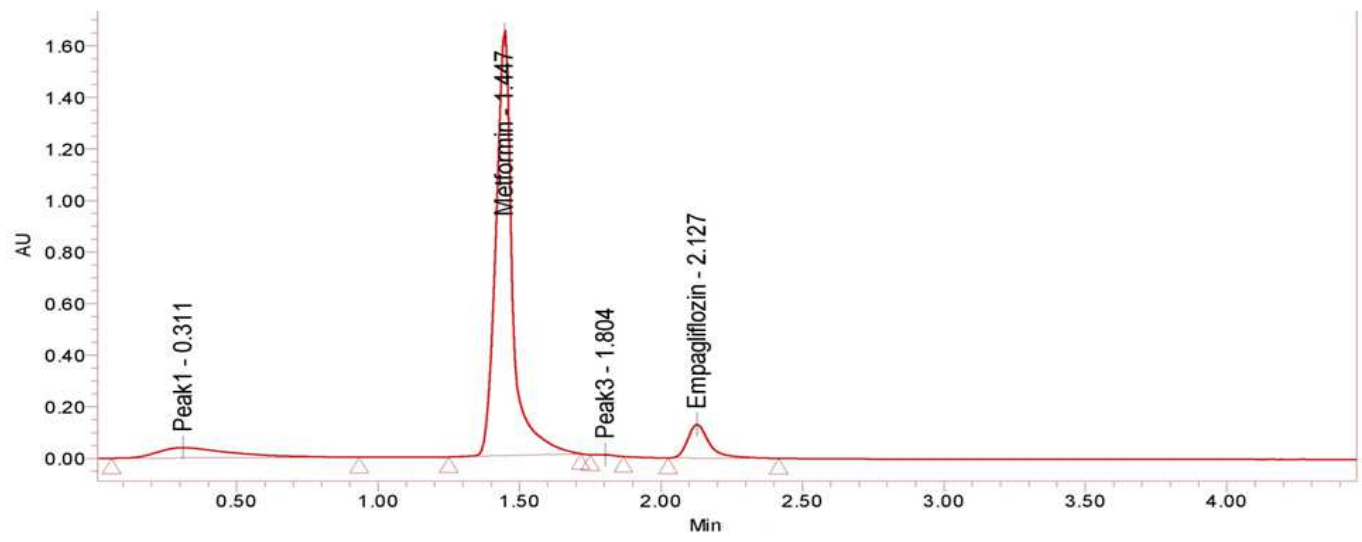

Fig. 10: Chromatogram of thermal degradation 


\section{CONCLUSION}

The newly developed UPLC method of metformin $\mathrm{HCl}$ and empagliflozin assay determination was found to provide faster retention time with a good resolution in the present study. A good linearity was obtained for both drugs $(500-2500 \mu \mathrm{g} / \mathrm{ml}$ and $5-25$ $\mu \mathrm{g} / \mathrm{ml}$ ) with a correlation coefficient of 0.994 and 0.998 for metformin $\mathrm{HCl}$ and empagliflozin respectively. The results of precision, recovery and ruggedness were within limits. Hence the method was successfully applied for degradation studies. The UPLC method of simultaneous estimation of metformin $\mathrm{HCl}$ and empagliflozin was found to be a novel, simple, precise, accurate and effective method. There were no UPLC methods reported till now on the above-mentioned combination drugs. Hence the developed method is suitable for the routine analysis and percentage degradation of pharmaceutical preparations containing these drugs either individually or in combination.

\section{CONFLICTS OF INTERESTS}

\section{Declare none}

\section{REFERENCES}

1. Maruthur NM, Tseng E, Hutfless S, Wilson LM, Suarez-Cuervo C, Berger $\mathrm{Z}$, et al. Diabetes medications as monotherapy or metformin-mased combination therapy for type 2 diabetes: a systematic review and meta-analysis. Ann Intern Med 2016;164:740.

2. National center for biotechnology Information. Pubchem compound Database; CID=14219; Available from: htpp:// pubchem.ncbi.nlm.gov/compound/14219. [Last accessed on 18 Feb 2017].

3. Abdul-Ghani MA, DeFronzo RA. Inhibition of renal glucose reabsorption: a novel strategy for achieving glucose control in type 2 diabetes mellitus. Endocr Pract 2008;14:782-90.

4. Grempler R, Thomas L, Eckhardt M, Himmelsbach F, Sauer A, Sharp DE, et al. Empagliflozin, a novel selective sodium glucose cotransporter-2 (SGLT-2) inhibitor: characterisation and comparison with other SGLT-2 inhibitors. Diabetes Obes Metab 2012;14:83-90.

5. National centre for biotechnology Information. Pubchem compound Database; CID=11949646. Available from: htpp://pubchem.ncbi.nlm.gov/compound/11949646. [Last accessed on 18 Feb 2017]

6. Diabetes (type 2)-empaglifozin. Appraisal consultation document. NICE technology appraisal; 2014.

7. Janet B, McGill. The SGLT2 inhibitor empagliflozin for the treatment of type 2 diabetes mellitus. Diabetes Ther 2014; 5:43-63.

8. Nair S, Wilding JP. Sodium-glucose cotransporter-2 inhibitors as a new treatment for diabetes mellitus. J Clin Endocrinol Metab 2010;95:34-42.

9. White JR. Apple trees to sodium glucose cotransporter inhibitors: a review of SGLT2 inhibition. Clin Diabetes 2010;28:5-10.

10. Christian Friedrich, Katrin Metzmann, Peter Rose, Michaela Mattheus, Sabine Pinnetti, Hans I Woerle. A randomized, openlabel, crossover study to evaluate the pharmacokinetics of empagliflozin and linagliptin after coadministration in healthy male volunteers. Clin Ther 2013;35:1.

11. Akula A, Prajwala N, Sandhya M. Development and validation of a RP-HPLC method for simultaneous estimation of metformin hydrochloride and gliclazide in bulk and combined dosage form. Int J Pharm Pharm Sci 2013;5:511-7.

12. Ayoub BM. UPLC simultaneous determination of empagliflozin, linagliptin and metformin HCl. R Soc Chem Adv 2015;5:95703-9.

13. Bhoomaiah B, Shree AJ. Development and validation of a RPHPLC method for simultaneous determination of metformin
$\mathrm{HCl}$ and miglitol in bulk and pharmaceutical formulation. Int J Pharm Pharm Sci 2014;6:135-41.

14. Madhukar A, Prince A, Kumar RV, Sanjeeva Y, Jagadeeshwar K, Raghupratap D. A simple and sensitive analytical method development and validation of metformin $\mathrm{HCl}$ hydrochloride by RP-HPLC. Int J Pharm Pharm Sci 2011;3:117-20.

15. Preethi Reddy N, Naga Thirumalesh C. RP-HPLC method development and validation for the simultaneous estimation of metformin $\mathrm{HCl}$ and canagliflozin in tablet dosage form. Int J Pharm Sci 2015;5:1155-9.

16. Padmaja N, Veerabhadram G. Method development and validation of a RP-HPLC method for the estimation of empagliflozin in the active pharmaceutical ingredient. Int J Pharm Sci Res 2015;7:724-7.

17. Prathap GM, Muthukumaran M, Krishnamoorthy B. Development and validation of simultaneously estimation of vildagliptin and metformin $\mathrm{HCl}$ hydrochloride by RP-HPLC in bulk and oral dosage form. Int J Adv Pharm Gen Res 2014;2:24-33.

18. Rajesh T, Lakshmi KS, Sharma S. Simultaneous determination of metformin $\mathrm{HCl}$ and pioglitazone by reversed phase HPLC in pharmaceutical dosage forms. Int J Pharm Pharm Sci 2009;1:162-6.

19. Shyamala, Nirmala K, Mounika J, Nandini B. Validated stability indicating RP-HPLC method for determination of empagliflozin. Der Pharm Lett 2016;8:2:457-64.

20. Bakshi M, Singh S. Development of validated stability indicating assay methods-critical review. J Pharm Biomed Anal 2002;28:1011-40.

21. Ravi Kant, Ramesh Bodla, Garima Kapoor, Rubina Bhutani. Development and validation of novel spectrophotometric methods for simultaneous estimation of pioglitazone and metformin in bulk and fixed dosage forms by the area under the curve and dual wavelength mode. Int J Appl Pharm 2016;8:48-53.

22. Mohammad Yunoos, Gowri Sankar D. A validated stability indicating a high-performance liquid chromatographic method for simultaneous determination of metformin $\mathrm{HCl}$ and dapagliflozin in bulk drug and tablet dosage form. Asian J Pharm Clin Res 2015;8:320-6.

23. Dhanya B Sen, Sen AK, Aarti Zanwar, Balaraman R, Seth AK. Determination of alogliptin benzoate and Metformin hydrochloride in tablet dosage form by simultaneous equation and absorption ratio method. Int $\mathrm{J}$ Pharm Pharm Sci 2015;7:380-3.

24. Prasanthi Chengalva, Angala Parameswari S, Aruna G. Development and validation of a RP-HPLC method for metformin hydrochloride and nateglinide in bulk and combined dosage form. Int J Pharm Pharm Sci 2016;8:267-71.

25. Mallikarjuna Rao N, Gowri Sankar D. RP-HPLC method for simultaneous estimation and stability indicating the study of metformin and linagliptin in pure and pharmaceutical dosage forms. Int J Pharm Pharm Sci 2015;7:191-7.

26. ICH guidelines for validation of analytical procedure: methodology and Harmonized Tripartite Guideline. Q2B ICH, Geneva; 1996. P. 1-10.

27. Geetha swarupa P, Lakshmana rao K, Prasad KRS, Suresh babu K. Development and validation of stability indicating a reversed phase high-pressure liquid chromatography method for simultaneous estimation of metformin and empagliflozin in bulk and tablet dosage form. Asian J Pharm Clin Res 2016;9:126-35.

\section{How to cite this article}

- $\quad$ N Madana Gopal, C Sridhar. A validated stability indicating a ultra-performance liquid chromatographic method for simultaneous determination of metformin hydrochloride and empagliflozin in bulk drug and tablet dosage form. Int J Appl Pharm 2017;9(3):45-50. 